\title{
Role of official statistics in situations of conflict and post-conflict
}

\author{
Hasan Abu-Libdeh \\ Palestinian Central Bureau of Statistics, B.O. BOX 1647, Ramallah, West Bank, Palestine \\ E-mail: hal@pcbs.pna.org
}

\section{Introduction}

The formal adoption of the ten Fundamental Principles of Official Statistics, 10FP, represents an important milestone in the process of empowering official statistics, and a turning point in the perception of the role of official statistics in the ultimate service of an informed citizenry. Indeed, the last decade of statistical development could be characterized as a persistent groundbreaking in the commitments, and extended measurement responsibilities, increasingly taken on by official statistics. During the decade, a multitude of indicators have been developed for monitoring progress in alleviating human suffering, culminating in the current efforts to establish a framework for measuring human rights and good governance within the mandate of official statistics.

The proactive role assumed by official statistics since then has lead to evolving the statistical function from a mere government owned function concerned mainly with satisfying the needs of governments, to a tool for measuring government performance and impact of policies on development and use of resources in a framework for the empowerment of citizens to become an informed citizenry. The proactive role has contributed to strengthening its "democratic" role and given an impetus to have statistics considered as a very important State function.

Systematic data collection and dissemination of relevant indicators of performance will eventually determine the degree of involvement of donor countries, regional commissions, and international agencies in official development assistance. This may leave develop- ing countries no choice but to pay more attention to the role of official statistics in these countries, and to the investments required to maintain a statistical function capable of a minimum data flow for monitoring impact of various interventions and progress in achieving goals of various global summits.

The challenge of maintaining a statistical function with minimum relevance is much greater, however, in situations of internal conflicts, wars, and military occupations, and in the immediate aftermath of these situations. While statistical development in normal situations is influenced mainly by the dynamics of national development planning and international strivings for various goals, statistical development in situations of conflict or post conflict is influenced mainly by strivings for national survival and preservation, empowerment and nationhood, and for qualification for membership in the international community of nations by meeting various obligations to report on the status of the emerging nation relative to various international goals and declarations.

In each of these situations key issues relating to the process and substance of the statistical function are worthy topics for discussion by the international community of statisticians for the sake of better understanding and for enhanced intervention in the framework of partnership and cooperation.

\section{National Statistics and obligations of the Global Statistical System during conflict}

"Official Statistics" has often been used by totalitarian regimes and belligerent occupiers as a tool for 
maintaining their grip on power and preservation of their authorities and control of "their subjects". Often, as in the case of the Israeli military occupation of West Bank and Gaza Strip since 1967, the regime tends to collect and disseminate "Official Statistics" in fields, which facilitate the maintenance of power, avoidance of international obligations, or the projection of progress in national socioeconomic realities of the indigenous population.

A statistical service in crises situations does not have the option of assuming a typical path in statistical production. It has to tailor the scope and content of its program with realities on ground. While the focus of statistics in countries torn by conflict, war, or belligerent occupation is often driven towards reporting on the direct cost of these conflicts in terms of human lives, loss of property, or violations of basic human rights on either side of the conflict, the function of statistics in these countries is bound by intrinsic need to promote survival, alleviation of human sufferings, and exposition of needs of vulnerable groups. An involved and proactive role should also include the responsibility of reporting about the humanitarian needs of vulnerable groups such as children and women, monitoring the impact of socioeconomic policies and practices (those of belligerent occupiers and indigenous players), and advocating (on the basis of quantitative assessments of the basic needs of population in conflict) for international protection of basic rights, not withstanding the role of maintaining international visibility of the national struggle.

The national statistical function in a war torn or occupied country has to be sensitive to potential misuses of its output. Political parties involved in an internal conflict as well as occupying powers may misuse the statistics to promote their own agendas or causes. In these situations, a delicate balance has to be found between working for national government whose legitimacy is in question, for professional independence of the statistical system, and for maintaining national identity in case of military occupation. The statistical function should strive to maintain confidence in its output during crises. It will have to innovate in defining stakeholders, meeting users expectations with sometimes conflicting agendas, and synthesizing users needs to avoid political bias while maintaining ties with governing bodies.

In the case of Palestine for example, statistical activities during the years of Israeli occupation between 1967 and 1994 were confined mainly to measuring deficiencies in the health care system and sporadic re- view of Palestinian living conditions. Repeated efforts to establish a more responsive statistical function were faced with tough measures from the Israeli military occupation forces. The Palestinian statistical system was established late 1993 upon signing the declaration of principles between the Israeli authorities and the PLO in September 1993. Its various functions were built on the basis of international experience in setting up and maintaining national statistical systems. During the last three years, however, additional responsibilities were added to the typical load of the statistical function due to the prevailing political and security conditions in Palestine. These included the setting up of special databases, which are not typically part of internationally agreed practices, or included in the international recommendations. Currently the Palestinian Central Bureau of Statistics collects data on a regular basis in areas such as household experiences of coping with the current crises, management of household consumption, quality and sufficiency of food intakes, primary health care availability, human rights violations of occupying forces, efficacy of international aide, and vulnerability statistics.

The collective obligations of the international community towards conflict resolution and protection of basic rights of populations in conflict or under occupation cover a broad set of dimensions, which affect the well being of these populations. This represents a good basis for extension of this collective responsibility to statistics, being a primary tool for measuring the degree of well being. Nations under occupation or conflict have every right to preserving numerical reflections of themselves, as well as for maintaining monitoring capacities of socioeconomic and political impact of prevailing conditions on the survival and well being of their populations. In fulfillment of this basic right, the international statistical community should take upon itself the responsibility of providing international protection for national efforts to measure, report, and monitor the different facets of survival and well being, as well as, commitment to use the nationally produced statistics for monitoring observance of social and economic rights, and impact of various policies on vulnerable groups.

The Global Statistical System (GSS) may influence the process of setting up national capacities in data collection, tabulation, and dissemination of a core set of statistics, which may represent an effective framework for monitoring the status and change of well being in such nations.

Political protection and support from the Global Statistical System for preserving at least a minimal statis- 
tical capacity at the national level may come directly through actions of material or professional support, as well as through solidarity and association with existing capacities through networking, communication, and moral support. Our own experiences of setting up and maintaining such a minimal statistical capacity in Palestine during the last two decades suggest that the proactive role of the international community is fundamental in maintaining visibility of national efforts for socioeconomic and political survival.

\section{National Statistics and obligation of Global Statistical System in post-conflict}

A nation in a post conflict situation is usually faced with serious challenges of reconstruction, rehabilitation, and development. Priorities, potentials and opportunities have rarely matched. Country authorities are usually squeezed between high expectations of its public and very limited resources, modest capabilities, and professional competence.

In this situation, the national statistical capacity is likely to suffer from the scarcity of national resources in trying to meet the needs of establishing and maintaining a minimal or core National Statistical System. It is the responsibility of national authorities to rebuild an open system of official statistics and charge it with tasks of establishing foundations for monitoring policies, empowering the citizenry through access to information, integrating the national statistical portrait with the global family of nations through commitments to provide statistics in response to international obligations.

In the case of Palestine, the task of establishing and producing official statistics had to compete with all sorts of fundamental priorities, in a middle of very scarce resource availability and long list of national needs. The three decades of Israeli military occupation have left the country with very little to work with in establishing a national statistical function. In fact, we had to cope with very little useful infrastructure to use in launching our own operations. Throughout the Israeli military occupation, they have applied a policy of depriving the endogenous population from any capacity in statistical production, while maintaining an extraterritorial data collection function. Even today, 10 years into Palestinian statistical mandate over the country, we are yet to gain access to databases, which were maintained by the Israeli authorities.

The role of the Global Statistical System in building, maintaining, and promoting newly emerging national statistical systems should not be limited to direct material support through bilateral or multilateral channels. The moral and political responsibility extends beyond the material or technical support, which often comes as a residual or on the sides of a larger donor recipient program of support, or even a restructuring program in fulfillment of a lending program. The Global Statistical System should initiate and lead a process of supporting the national efforts for rebuilding the country's NSS, of facilitating the integration of the newly emerging NSS in the GSS, of promoting recognition of challenges and potentials of the new system, of supporting and promoting partnership in establishing the statistical infrastructure, of facilitating transfer of know-how, and of providing political support for establishing national versions of the 10 Fundamental Principles.

Partnership in establishing, promoting, maintaining, and sustaining a decent NSS will certainly help countries enhance their capabilities of promoting evidencebased policies and democratic principles.

\section{A proactive role of the Global Statistical System and National Statistical Systems}

Until recently when the 10 Fundamental Principles were adopted by the Statistical Commission, the Global Statistical System has chosen to avoid expression of opinion or to take a stand on issues of abuse of official statistics, of destruction of national archives, of politicisation of the statistical profession and of statisticians in jeopardy in their own countries, and to side with national statistical systems in crises. In our opinion, the strength of the 10FP lies in the fact that they represent the strongest political statement in support of official statistics from the professional body applying these principles.

With regard to the international statistical community, the adoption of these principles obliges this community to assume a more involved and proactive role in the protection and support of the National Statistical System in their strivings to establish statistics as a public good. In this regard, the ISI and IAOS are very suitable forums to take the lead and be much more actively present in the field of statistical ethics, as well as, political, and moral support for official statistics worldwide.

National statistical systems in nations emerging from belligerent occupation, war, or internal conflict look up to the global family for recognition, political support, sustainable capacity building, protection, ac- 
cess to the international experience and expertise, coordination and use of own outputs, and moral responsibility to preserve an enabling environment for integrating NSS in the global family. Efforts should be made and resources should be committed to encourage and support statistics and NSS to be leaders of change and to assume a progressive and groundbreaking role in situations of conflict-post-conflict. The framework of this role may require the profession to move from a mere static recording of measurements to active monitoring. Key steps in turning a NSS into a progressive system may include sets of measure to be taken in specific areas, including:

- Measures of inclusiveness of inputs and diversity of statistical coverage, to move beyond the classical contents of national programming. This may include extension to hot areas and to linking development indicators to those of human rights and governance.

- Measures of achieving true independence from government influence on the substance of programs and functions. This may involve breaking a way from the flat understanding of achieving independence through administrative autonomy.

- Measures of increased access potential in service of an ultimate concept of knowledge for ALL, including the treatment of statistics as a public good.

- Measures for an increased an active national coordination in service of increased ownership of the national statistical program, in addition to measures for embracing international involvement through reporting on the national experiences and meeting reporting obligations regarding various global issues.

- Measures to move the statistical function from being mainly driven by the collective needs of governments to collective rights of various stakeholders to relevant information.

- Measures for projecting the statistical function as a reflection of national aspirations and as a fulfillment of vital must for maintaining true nationhood.
These measures may represent another milestone to be covered ten years after the adoption of the 10 Fundamental Principles in 1994, in the path for a leader "groundbreaking" role for official statistics at national level. Obviously, the international community of statisticians will have to debate on these issues for generalization and possible adoption as the second generation of our Fundamental Principles of Official Statistics. May be the time has come for chief statisticians around the world, together with professional bodies like IAOS to take up these issue.

Finally, In the aftermath of the IAOS 2000 triumphal embracing of the issues of linkages between statistics, development, and human rights, official statistics and chief statisticians might not be so far from setting up a sort of a world monitoring system, having the function to support statistical systems in crises, and to reveal inconsistencies or bad practices in national statistical systems. This monitoring role could be taken over by the IAOS, which brings together almost all chief statisticians of the world.

\section{Résumé}

The adoption of the ten fundamental principles of official statistics represents an important milestone in the process of empowering official statistics. These principles, however, fall short of providing a framework for reasonable development of statistical functions in situations of conflict or post-conflict. Statistical development in countries passing through crises should be viewed as a collective responsibility of the international statistical community. For this to happen, official statistics should play a more involved and proactive role in measuring, reporting, and monitoring conditions of nations in crises. We discuss rights and obligations of National Statistical Systems and the Global Statistical System, and propose certain measures for empowering official statistics at national level as a leader of change. We invite the international community of statisticians to assume responsibility for promoting a second generation of the ten fundamental principles of official statistics, on the basis of a new groundbreaking role. 